\title{
Plasma-Derived Graphene-Based Materials for Water Purification and Energy Storage
}

\author{
Nikolas Natter ${ }^{1}$, Nikolaos Kostoglou ${ }^{1, *(1)}$, Christian Koczwara ${ }^{2}{ }^{(}$, Christos Tampaxis $^{3}$,

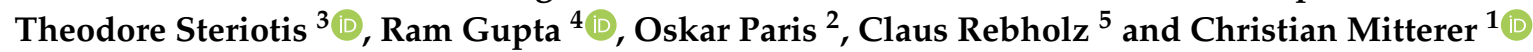 \\ 1 Department of Materials Science, Montanuniversität Leoben, 8700 Leoben, Austria; \\ nikolas-rupert.natter@stud.unileoben.ac.at (N.N.); christian.mitterer@unileoben.ac.at (C.M.) \\ 2 Institute of Physics, Montanuniversität Leoben, 8700 Leoben, Austria; \\ christian.koczwara@unileoben.ac.at (C.K.); oskar.paris@unileoben.ac.at (O.P.) \\ 3 Institute of Nanoscience and Nanotechnology, National Center for Scientific Research Demokritos, \\ 15310 Athens, Greece; c.tampaxis@inn.demokritos.gr (C.T.); t.steriotis@inn.demokritos.gr (T.S.) \\ 4 Department of Chemistry, Pittsburg State University, Pittsburg, KS 66762, USA; ramguptamsu@gmail.com \\ 5 Department of Mechanical and Manufacturing Engineering, University of Cyprus, 1678 Nicosia, Cyprus; \\ claus@ucy.ac.cy \\ * Correspondence: nikolaos.kostoglou@unileoben.ac.at; Tel.: +43-6811-0554-221
}

Received: 2 March 2019; Accepted: 28 March 2019; Published: 3 April 2019

\begin{abstract}
Several crucial problems, such as rapid population growth and extended demands for food, water and fuels, could lead to a severe lack of clean water and an energy crisis in the coming decade. Therefore, low-cost and highly-efficient technologies related to filtration of alternative water supplies (e.g., purification of wastewater and water-rich liquids) and advanced energy storage (e.g., supercapacitors) could play a crucial role to overcome such challenges. A promising class of solid materials for these purposes is exfoliated graphene, and more specifically, its nanoporous forms that exhibit large specific surface areas and pore volumes. In the current work, two plasma-exfoliated graphene-based materials with distinctive morphological and porosity features, including non-porous and low-specific surface area platelets versus nanoporous and high-specific surface area flakes, were tested as filters for water purification purposes (i.e., decolourization and deacidification) and as electrodes for supercapacitors (i.e., ion electrosorption). The findings of this study suggest that a nanoporous and large specific surface area graphene-based material promotes the water purification behaviour by removing contaminants from water-based solutions as well as the energy storage performance by confining ions of aqueous electrolytes.
\end{abstract}

Keywords: carbon powders; nanoporous graphene; water filters; decolourization; electrodes; supercapacitors

\section{Introduction}

Exfoliated graphene, a two-dimensional single-layer of $\mathrm{sp}^{2}$-bonded carbon atoms distributed in hexagonal cells, has been the subject of considerable research since the beginning of the 21st century due to its unique electronic, thermal, optical and mechanical properties [1,2]. Few-layer graphene (FLG), composed of a limited number of stacked graphene layers, can be also produced in a porous form [3], thus providing high specific surface areas and pore volumes combined with tunable pore sizes [4]. Apart from these surface-related features, porous graphene-based materials possess other significant advantages such as low densities, reasonably good thermochemical stability, excellent recyclability, environmental friendliness and non-toxicity [5,6]. Micro-mechanical exfoliation of pyrolytic graphite [7], chemical vapor deposition via cracking of carbon sources [8], chemical 
reduction of graphite oxide [9] as well as electrochemical exfoliation of graphite [10] are the main production routes for graphene-based materials. However, the plasma-induced exfoliation of natural graphite can be considered an as efficient, not solution-based, catalyst-free, cost-effective and environmental-benign approach to produce FLG materials of high-purity in bulk quantities. Using this method, the generated plasma modifies the graphitic surface either by physical ablation or chemical functionalization, thus allowing the production of graphene-based materials with different porosities (ranging from non-porous to highly nanoporous) and surface chemistries (e.g., functional groups, dopants, etc.) [11,12].

The production of microporous (i.e., pore widths below $2 \mathrm{~nm}$ ) FLG materials for selective gas, liquid and ion adsorption, and in particular for efficient water purification and energy storage, has been the topic of on-going investigations [13-16]. In the next decade, the rapid increase of the global population, fast-growing demands for food and water, extended droughts and scarcity of freshwater sources (i.e., they make up only $0.5 \%$ of world's overall water resources) will probably lead to a severe lack of clean water $[12,14,15]$. In addition, the intensively-growing demands for energy in combination with the finite amount of available fossil fuels resources (oil, natural gas, coal, etc.) could deteriorate even more the currently negative energy landscape. Therefore, low-cost and highly-efficient technologies for filtration of alternative water supplies (purification of wastewater and water-rich liquids, desalination of sea water, etc.) and advanced energy storage (supercapacitors, hybrid batteries, etc.) might provide potential solutions for future water and energy crises [17-20]. Apart from the classical purification techniques (e.g., sand filtration, sedimentation, etc.), there are some other methods that could yield potential for high-performance filtering. Among those, distillation and reverse osmosis are particularly of importance [21-23]. Carbon nanotube membranes were studied for water permeation and flow via reverse osmosis towards wastewater treatment and sea water desalination [24-26]. Granular activated carbon, which often contains Si due to its excellent antibacterial properties [6], is also used as effective adsorbent material in commercial water filters [27]. In contrast to standard routes of storing electrical energy in batteries, electrical double-layer capacitors, also called supercapacitors, use an operation principle which is based on a simple potential-induced electrosorption of ions from ionic liquids as well as aqueous or organic electrolytes onto the surface of charged electrodes (usually carbons) [28]. Furthermore, when aqueous electrolytes are used the systems are non-toxic and environmental friendly [18].

In this work, two plasma-derived graphene-based powders with different porosity characteristics (i.e., nanoporous and large specific surface area flakes versus non-porous and low specific surface area platelets) were examined for two different applications. The first one involved water purification (i.e., decolourization and deacidification) based on simple and reproducible filtering experiments using Coca-Cola ${ }^{\circledR}$ (Atlanta, GA, USA) as a coloured water-rich liquid and graphene powders as filters. Coca-Cola ${ }^{\circledR}$ is one of the most popular soft beverages consumed worldwide with more than 1.9 billion servings per day [29]. This product includes various ingredients with the basic ones being carbonated water $(\sim 90 \%)$, sugar (a mixture of glucose and fructose), caramel colour, phosphoric acid, caffeine and natural flavours [30]. The characteristic "brownish" colour is specifically attributed to the caramel colour E150d, which is an acid-proof sulphite ammonia-based caramel [31]. Dispersion and wettability tests were also carried out to evaluate the interaction of these materials with distilled water and other solvents (e.g., ethanol) along with $\mathrm{pH}$ measurements using $\mathrm{pH}$ test strips in a basic effort to evaluate the acidity of the filtered water. The second application was related to electrochemical energy storage (i.e., ion electrosorption) by assembling electrical double-layer capacitor devices consisting of an aqueous electrolyte and graphene-based electrodes. The energy storage performance was evaluated by cyclic voltammetry (CV) and electrochemical impedance spectroscopy (EIS) measurements. The morphological, structural and porosity properties of the selected powders were characterized by scanning electron microscopy (SEM), X-ray diffraction (XRD), small-angle $\mathrm{X}$-ray scattering (SAXS) and nitrogen $\left(\mathrm{N}_{2}\right)$ gas adsorption/desorption measurements at $77 \mathrm{~K}$, respectively. 


\section{Materials and Experimental Methods}

The two graphene powders investigated in this study were provided by Perpetuus Carbon Technologies (Ammanford, United Kingdom). These included: (a) graphene nanoplatelets (GNP) with $<5 \mu \mathrm{m}$ diameter, $<50 \mathrm{~nm}$ thickness, $2 \mathrm{wt} . \%-\mathrm{COOH}$ content and $96 \%$ purity and (b) few-layer graphene flakes (FLG) with stacks of 3-6 layers, $<2 \mu \mathrm{m}$ diameter, $<3 \mathrm{~nm}$ thickness, $2 \mathrm{wt} . \%-\mathrm{COOH}$ content and $96 \%$ purity. Both materials were produced by exposing natural flake graphite in argon plasma for two different time periods using a custom-made multi-electrode dielectric barrier discharge plasma reactor, as described elsewhere [4,32]. Figure 1 (upper left) allows to visualize the difference in the volume occupied from $2 \mathrm{~g}$ of each graphene powder. The packing density in a fixed-volume container $\left(2 \mathrm{~mL}\right.$ ) was estimated to be $\sim 0.18$ and $\sim 0.22 \mathrm{~g} / \mathrm{cm}^{3}$ for GNP and FLG, respectively.

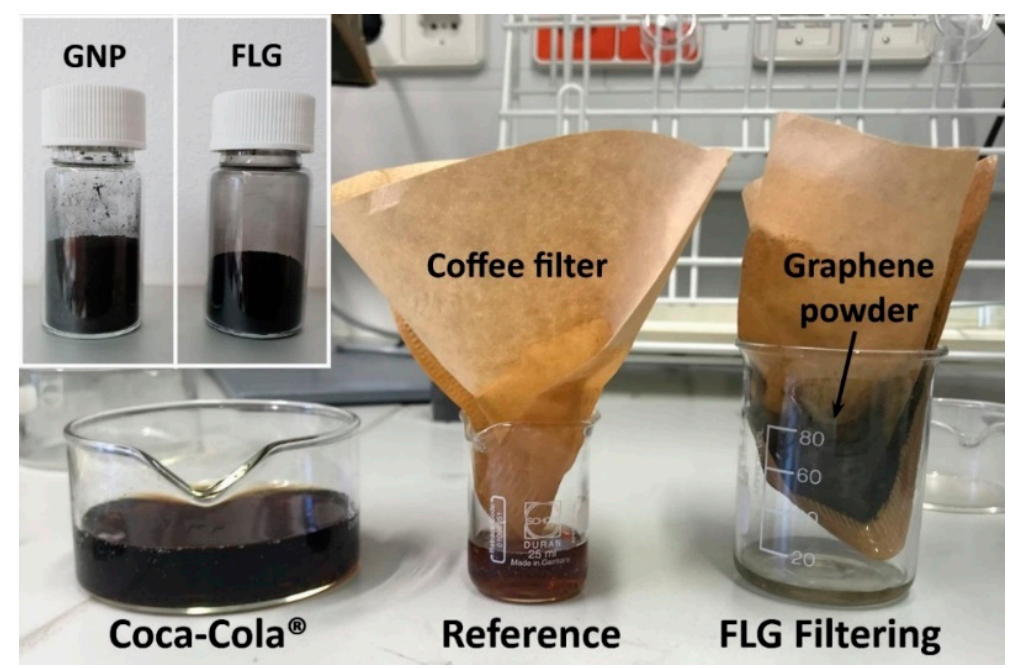

Figure 1. Difference in the volume occupied by $2 \mathrm{~g}$ of GNP and FLG powders (upper left); filtration setup for water purification showing a coffee filter filled with graphene powder (right), an empty coffee filter used for reference (middle) and the pure Coca-Cola ${ }^{\circledR}($ left).

The surface morphology was studied by using a Quanta 200 scanning electron microscope (FEI, Hillsboro, OR, USA) at acceleration voltages of 25-30 kV and a working distance of $10 \mathrm{~mm}$. XRD measurements were performed using a D8 Advance diffractometer (Bruker-AXS, Karlsruhe, Germany) equipped with $\mathrm{Cu} \mathrm{K} \alpha$ radiation $(\lambda \sim 1.54 \AA)$ at $40 \mathrm{kV}$ voltage and $40 \mathrm{~mA}$ current. The X-ray diffractograms were recorded using a continuous scan speed mode between the diffraction angles $(2 \theta)$ of $10^{\circ}$ and $60^{\circ}$, a $0.01^{\circ}$ step width and a $0.5^{\circ} / \mathrm{min}$ scan speed. SAXS measurements were performed with a N8 Horizon SAXS (Bruker-AXS, Karlsruhe, Germany) facility operated with an X-ray micro-source at $50 \mathrm{kV}$ voltage and $1 \mathrm{~mA}$ current delivering $\mathrm{Cu} \mathrm{K} \alpha$ radiation. The SAXS curves were recorded with a Vantec 500 detector and azimuthally averaged, using the software Fit2D [33], leading to the scattered intensity as a function of the scattering vector $(Q=4 \pi \sin \theta / \lambda)$. The resulting scattering curves were normalized to the corresponding transmission value measured with a glassy carbon standard [34]. $\mathrm{N}_{2}$ gas adsorption/desorption isotherms were recorded at $77 \mathrm{~K}$ using a Autosorb MP-1 gas sorption analyzer (Quantachrome Instruments, Boynton Beach, FL, USA), a liquid $\mathrm{N}_{2}$ bath and ultra-pure $(99.999 \%) \mathrm{N}_{2}$ gas. Prior to the measurements, samples of $\sim 50 \mathrm{mg}$ were degassed under vacuum $\left(10^{-6}\right.$ mbar) at $250{ }^{\circ} \mathrm{C}$ for $12 \mathrm{~h}$ to remove any physisorbed species/contaminants from the surface of the materials. Brunauer-Emmet-Teller (BET) areas were calculated by following the relevant consistency criteria [35]. The pore size distribution analysis was carried out by using the equilibrium the Quenched Solid Density Functional Theory (QSDFT) kernel for slit-shape pores [36].

Powder dispersion tests were carried out in distilled water and ethanol by mixing $50 \mathrm{mg}$ of powder with $100 \mathrm{~mL}$ of solvent in each case. The solutions were placed in an ultrasonic bath for $10 \mathrm{~min}$ to achieve a more uniform mixture. Digital photographs were taken at regular intervals for up to 44 
days. Ethanol was used for comparison as a common liquid for carbon powder dispersion experiments. Wettability tests on graphene electrodes/films were performed using a DSA100 contact-angle device (Krüss, Hamburg, Germany) and distilled water. The electrodes were prepared by mixing the graphene powders with $10 \mathrm{wt}$ \% polytetrafluoroethylene (PTFE; Sigma-Aldrich, St. Louis, Missouri, USA) binder in distilled water. The received pastes were rolled in a rolling press (MTI Corporation, Richmond, CA, USA) until they reached a thickness of $300 \pm 20 \mu \mathrm{m}$ and then dried for $24 \mathrm{~h}$ at $120^{\circ} \mathrm{C}$ and $5 \mathrm{mbar}$ in a vacuum oven. For the wettability tests, a water droplet of $2 \mu \mathrm{L}$ was placed onto the surface of the as-prepared graphene electrodes. The contact angles were recorded once the droplet was in contact with the surface by taking a digital picture. Additionally, the time required for full sorption of the droplets within the films was measured and respective pictures were taken every $2 \mathrm{~min}$.

The purification experiments were performed by placing $1 \mathrm{~g}$ of graphene powder in a commercial coffee filter (Melitta Filtertüten Original $1 \times 2$ ) mounted on a glass flask. An empty coffee filter with no powder was used as a reference. This simple experimental setup is illustrated in Figure 1. Coca-Cola ${ }^{\circledR}$ was gradually poured on top of the filter, passed through the powder and the product was collected after a few minutes. Then, the filtered water was re-poured once again onto the filter and passed through the powder for a second filtering cycle. Digital pictures of the products were taken after both cycles. Commercial $\mathrm{pH}$ paper strips were dipped in the filtered liquids to observe changes in their $\mathrm{pH}$ value.

Electrochemical characterization of the electrodes was performed with a Reference 600 potentiostat (Gamry, Warminster Township, PA, USA) using a custom-built cell with a polyether ether ketone (PEEK) housing and Ti pistons connected to two separate electrical contacts. The pistons are spring loaded to apply a well-defined constant pressure on the actual supercapacitor cell built between these pistons [37]. All measurements were performed with an asymmetric half-cell setup with an approximately 8-times oversized counter electrode (CE) as a quasi-reference [38], consisting of commercially available activated carbon (YP-80F, Kuraray Chemical Co., Osaka, Japan) electrodes prepared as described above with a reduced amount of PTFE binder ( $5 \mathrm{wt} . \%)$. The cell was built as a multi-layered assembly with two Pt current collectors, a CE, a working electrode (WE) and a glass fiber separator (Whatman GF/A) in between the electrodes. The WE had a diameter of $6 \mathrm{~mm}$ and a thickness of $300 \pm 20 \mu \mathrm{m}$ and an aqueous $1 \mathrm{M}$ caesium chloride $(\mathrm{CsCl})$ solution was used as the electrolyte. Cyclic voltammetry $(\mathrm{CV})$ measurements were performed in the range of $\pm 0.6 \mathrm{~V}$ against the quasi reference. $\mathrm{CV}$ curves were recorded for various scan rates ranging from 0.5 up to $100 \mathrm{mV} / \mathrm{s}$. The specific capacitance (C) was calculated according to:

$$
C=\frac{\int_{t_{0}}^{t_{1}} I d t}{m \cdot \Delta U}
$$

where $I$ is the current, $m$ is the mass of the WE and $\Delta U$ is the voltage window. EIS studies were performed at $0 \mathrm{~V}$ with a root-mean-square (RMS) value of $\pm 5 \mathrm{mV}$ over a frequency range from $10 \mathrm{mHz}$ to $100 \mathrm{kHz}$ with 10 points per decade. Galvanostatic charge-discharge (GCD) measurements were performed in the potential range between -0.6 and $+0.6 \mathrm{~V}$ with different specific currents ranging from 0.25 up to $1 \mathrm{~A} / \mathrm{g}$.

\section{Results and Discussion}

\subsection{Morphological, Structural and Porosity Studies}

SEM images of the GNP and FLG powders are shown in Figure 2a,b. The platelets of the GNP material (Figure 2a) are agglomerated and exhibit a smooth surface. In contrast, in Figure $2 b$ the surface of the FLG material looks much rougher and defective due to the extended plasma ablation procedure. As supported by the $\mathrm{N}_{2}$ adsorption data presented below, the highly-defective structure of the FLG sample provides a much larger specific surface area as compared to the GNP sample. 

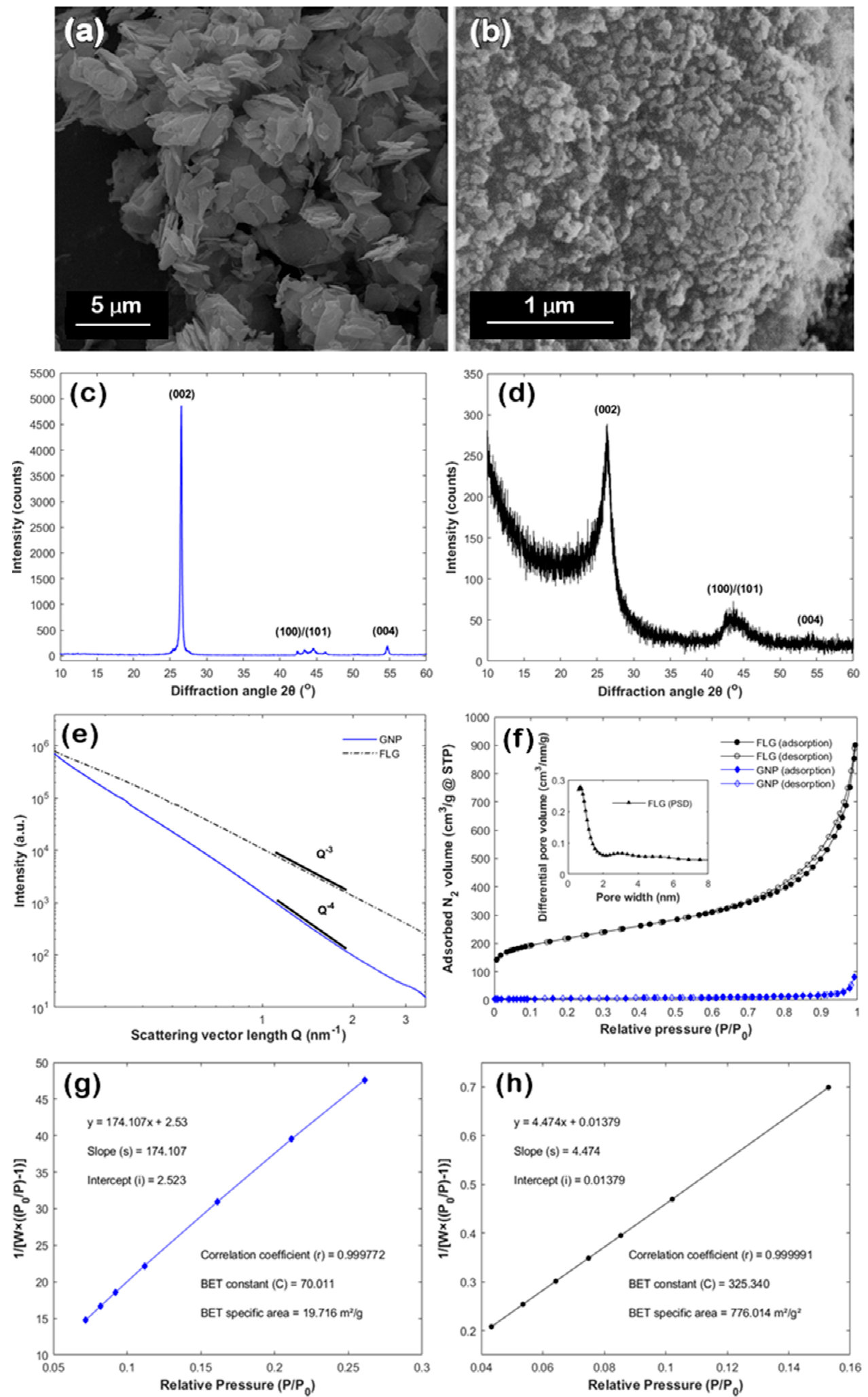

Figure 2. SEM images of the plasma-derived (a) GNP and (b) FLG powders, X-ray diffractograms for (c) GNP and (d) FLG, (e) SAXS curves, (f) $\mathrm{N}_{2}$ adsorption/desorption isotherms recorded at $77 \mathrm{~K}$ and linear multi-point BET plots for (g) GNP and (h) FLG.

X-ray diffractograms of the GNP and FLG powders are presented in Figure 2c,d. As shown in Figure 2c, the GNP powder appears to be highly-crystalline and exhibits a similar structure to 
graphite (JCPDS card no 75-1621). The XRD peaks infer that the GNP consists mainly of graphitic carbon without significant presence of impurities. Figure $2 d$ indicates that the FLG powder is much less crystalline and much more defective than the GNP, which is in good agreement with the SEM observations. Except for the main stacking peak at about $26^{\circ}$ referring to the (002) graphitic reflection and the less intense peaks at about $43^{\circ}$ and $54^{\circ}$ representing the $(100) /(101)$ and (004) crystal planes, respectively, no evidence of other species was detected.

The SAXS curve of the GNP powder (Figure 2e) shows the typical decay intensity $\left(I \propto \mathrm{Q}^{-4}\right)$ for a two-phase system with a smooth surface described by Porod's law [39]. In contrast, the FLG sample shows a clear deviation from this ideal system with the intensity decaying rather with $I \propto Q^{-3}$. This can be either explained by a fractal pore structure [40] or alternatively by electron density fluctuation due to imperfect stacking and defects in the graphene sheets [41,42]. Such a result is expected due to the controlled "destruction" of the carbon surface via plasma ablation and is consistent with the SEM observations. Even though, no quantitative analysis of the SAXS data was performed [43], they support the $\mathrm{N}_{2}$ sorption analysis of very small pores and a much higher specific surface area of the FLG sample as compared to GNP.

The $\mathrm{N}_{2}$ adsorption/desorption isotherms recorded at $77 \mathrm{~K}$ for the degassed FLG and GNP powders are shown in Figure $2 \mathrm{f}$. The much higher $\mathrm{N}_{2}$ uptake of the FLG at low relative pressures $\left(\mathrm{P} / \mathrm{P}_{0}<0.01\right)$ is attributed to its microporosity (i.e., pore widths $\left.<2 \mathrm{~nm}\right)[4]$. In addition, the formation of a small hysteresis loop between the adsorption and desorption curves for the FLG is related to capillary condensation of $\mathrm{N}_{2}$ gas within mesopores (i.e., pore sizes of 2-50 nm) [44]. The adsorbed $\mathrm{N}_{2}$ amounts increase abruptly for both powders at higher relative pressures $\left(\mathrm{P} / \mathrm{P}_{0}>0.95\right)$ without reaching a clear "plateau" due to adsorption onto external surfaces and/or condensation in macropores (i.e., pore widths $>50 \mathrm{~nm}$ ) $[44,45]$. Therefore, the $\mathrm{N}_{2}$ adsorption behaviour indicates that the GNP is mainly non-porous (macropores may exist though), while the FLG combines microporous, mesoporous and macroporous characteristics. This is supported by the QSDFT-based pore size distribution analysis (see inset of Figure 2f), which indicates the existence of sub-nanometer pores (showing a peak at around $0.7 \mathrm{~nm}$ ). The BET area of the degassed FLG powder is almost 40 times higher than that of GNP (i.e., $\sim 776 \mathrm{~m}^{2} / \mathrm{g}$ vs. $\sim 20 \mathrm{~m}^{2} / \mathrm{g}$ ). The linear multi-point BET plots of the degassed GNP and FLG powders are presented in Figure $2 \mathrm{~g}, \mathrm{~h}$, respectively.

\subsection{Dispersion and Wettability Studies}

The dispersions of GNP and FLG powders in distilled water and ethanol are exemplified in Figure 3. On the one hand, GNP was fully dispersible in ethanol but formed some sort of gel with distilled water (i.e., a very thick viscous liquid) right after preparing the dispersions, as indicated in Figure 3a. After $48 \mathrm{~h}$ (Figure 3b), the dispersion segregated completely in ethanol by forming a thin layer both on the top and bottom of the solution, while it segregated partially in distilled water with some powder still appearing on the top of the solution. The same behaviour was observed even after 44 days as seen in Figure 3c. In contrast, FLG is fully dispersible both in distilled water and ethanol, as shown in Figure 3d. After $48 \mathrm{~h}$ (Figure 3e) and even after 44 days (Figure 3f), there is no indication of separation between the FLG powder and the solvent [46]. The findings obtained by water contact angle measurements for the as-prepared GNP and FLG thin films are summarized in Figure 3g. The GNP electrode had a higher contact angle with the water droplet as compared to the FLG electrode (i.e., $\sim 126^{\circ}$ for GNP and $\sim 87^{\circ}$ for FLG). Contact angles larger than $90^{\circ}$ indicate a hydrophobic behaviour while those smaller than $90^{\circ}$ are characteristic for a hydrophilic behaviour [47]. The reason for the (slight) hydrophilicity of the FLG sample might be related to the defect-induced highly-porous surface of the FLG sample in contrast to the non-porous GNP surface. Furthermore, the time it took the samples to fully soak the water droplet was shorter for FLG than for GNP (i.e., 16.5 min for GNP and $12.5 \mathrm{~min}$ for FLG). 


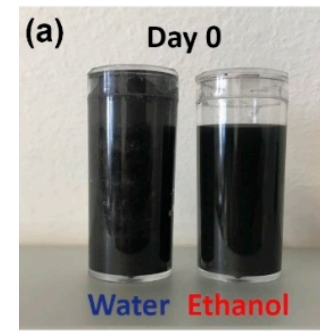

(d)

\section{(b)}

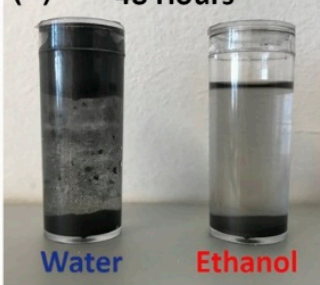

(e)

48 Hours

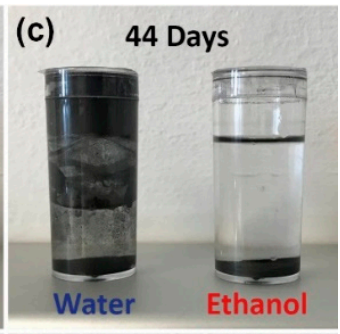

(f)
44 Days
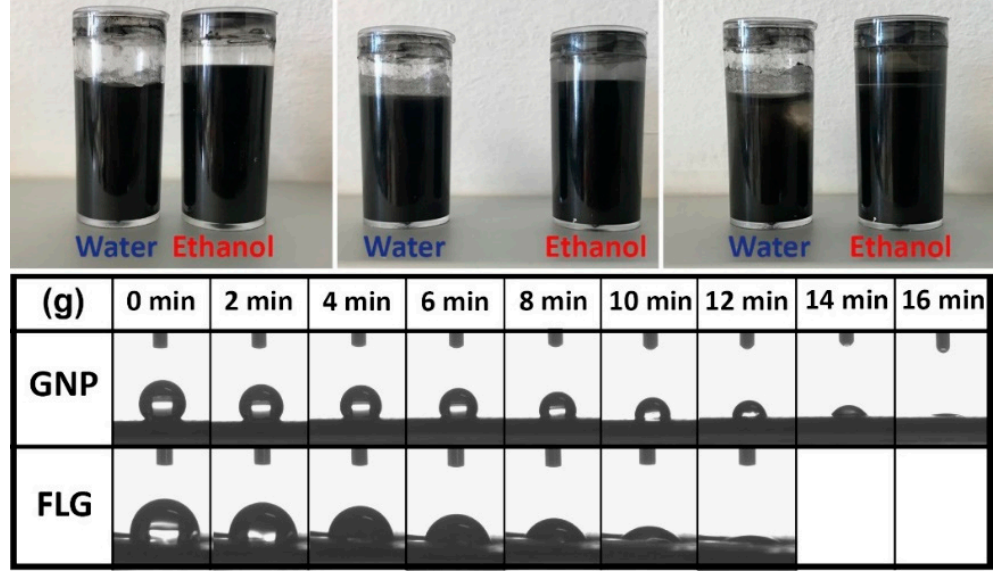

Figure 3. Dispersions of $(\mathbf{a}-\mathbf{c})$ GNP and (d-f) FLG powders with distilled water and ethanol directly after mixing, after $48 \mathrm{~h}$ and after 44 days, respectively; (g) digital pictures taken every 2 min for the water contact angle measurements of the as-prepared GNP and FLG thin films.

\subsection{Filtration Studies}

The purification behaviour of the GNP and FLG powders towards coloured water-based liquids such as a Coca-Cola ${ }^{\circledR}$ is demonstrated in Figure 4. Coca-Cola ${ }^{\circledR}$ filtered only with a coffee filter is included as a reference in Figure 4a. The GNP powder showed no effective filtering behaviour and even contaminated the final product (i.e., black-coloured GNP-Coca-Cola ${ }^{\circledR}$ mixture in Figure $4 \mathrm{~b}$ ). The FLG powder, however, made the filtered Coca-Cola ${ }^{\circledR}$ much more transparent, although some very small powder particles were able to pass through the filter (see Figure $4 \mathrm{~b}$ ). A second filtering cycle was repeated using the same FLG-based filters (from the first cycle) to further purify the water-based liquid. As shown in Figure 4c, the second-time filtered Coca-Cola ${ }^{\circledR}$ product got even more transparent and did not show any observable signs of powder contamination. Therefore, the FLG-based filter was able to decolourize the Coca-Cola ${ }^{\circledR}$ after two cycles of filtration based on visual inspection.

The outcome of $\mathrm{pH}$ measurements using commercial $\mathrm{pH}$ paper strips is presented in Figure $4 \mathrm{~d}$. The $\mathrm{pH}$ value lies between 2 and 3 by filtering the Coca-Cola ${ }^{\circledR}$ with only a coffee filter; i.e., without FLG powder. It should be noted that Coca-Cola ${ }^{\circledR}$ has a $\mathrm{pH}$ value of $\sim 2.5$ according to the literature [48], which is attributed to the presence of phosphoric acid. However, when the FLG powder was used as a filtering material, the $\mathrm{pH}$ value moved closer to the neutral side of the $\mathrm{pH}$ scale (i.e., $\mathrm{pH}$ value 5-6 after two cycles vs. $\mathrm{pH} \sim 7$ for pure water). Even though these results are only a qualitative indication based on a visual analysis of these strips, there is strong evidence that the FLG powder partially neutralizes the acidic behaviour of the Coca-Cola ${ }^{\circledR}$. 


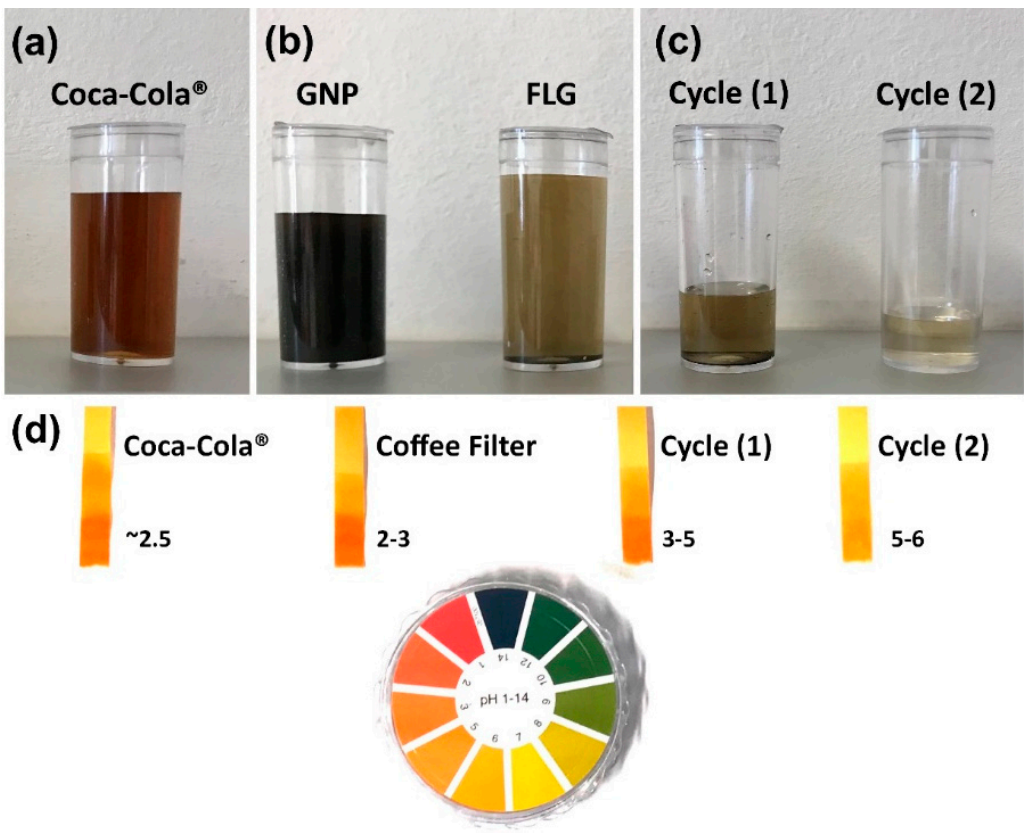

Figure 4. (a) Coca-Cola ${ }^{\circledR}$ filtered only with a coffee filter, (b) water-based liquids derived from Coca-Cola ${ }^{\circledR}$ upon filtration with GNP and FLG powders (first purification cycle), (c) water-based liquids derived from Coca-Cola ${ }^{\circledR}$ following two cycles of filtration with the FLG powder and (d) pictures of commercial $\mathrm{pH}$ paper strips; from left to right: pure Coca-Cola ${ }^{\circledR}$ (value extracted from literature [48]), Coca-Cola ${ }^{\circledR}$ filtered only with a coffee filter and Coca-Cola ${ }^{\circledR}$ filtered with FLG powder after one and two filtration cycles.

\subsection{Electrochemical Studies}

Besides filtration, the same graphene-based materials were also evaluated with respect to energy storage purposes. The electrochemical performance data of the GNP- and FLG-based supercapacitor electrodes using $1 \mathrm{M} \mathrm{CsCl}$ aqueous electrolyte are summarized in Figure 5. The $\mathrm{CV}$ curves for different scanning rates (i.e., 1, 10 and $100 \mathrm{mV} / \mathrm{s}$ ) appear to be almost symmetric (see Figure 5a). Specifically, for the FLG sample, the rectangular shape of the CV curves and the gravimetric capacitance values indicate a proper capacitive behaviour and its suitability as an electrode material for supercapacitor devices. The rate handling tests between 0.5 and $100 \mathrm{mV} / \mathrm{s}$ are presented in Figure $5 \mathrm{~b}$. A maximum gravimetric capacitance of $\sim 57 \mathrm{~F} / \mathrm{g}$ and $\sim 5 \mathrm{~F} / \mathrm{g}$ was recorded for FLG and GNP electrodes, respectively, for the scanning rate of $0.5 \mathrm{mV} / \mathrm{s}$. The capacitance values drop by 42 and $31 \%$ for FLG and GNP, respectively, upon increasing the scanning rate up to $100 \mathrm{mV} / \mathrm{s}$, as seen in the inset of Figure $5 \mathrm{~b}$. The ion diffusion characteristics in the porous FLG can be different from the non-porous GNP, thus leading to a more significantly reduced relative capacitance for FLG at higher scan rates. In any case, the FLG outperforms the GNP in terms of capacitance (ratio $~ 11.5: 1$ at $0.5 \mathrm{mV}$ ) due to its nanoporous structure and consequently much larger available specific surface area (i.e., $\sim 776$ vs. $\sim 20 \mathrm{~m}^{2} / \mathrm{g}$, respectively). Recent experimental and computational studies suggested that charged ions can be stored more effectively in sub-nanometer pore widths with the highest degree of confinement $[49,50]$. With respect to their electrochemical cyclic stability, both samples showed no capacitance loss after 400 charge/discharge cycles. The Nyquist plots, presented in Figure 5c, highlight the typical electrical double-layer behaviour and an almost ideal capacitive behaviour for the FLG. The low equivalent series resistance for both samples (i.e., 0.10 and $0.13 \Omega \cdot \mathrm{cm}^{2}$ for GNP and FLG, respectively), as shown in the inset of Figure $5 c$, suggests a good conductivity and low internal resistance for the half-cell setup [51]. The GCD curves, shown in Figure 5d, indicate a nearly linear behaviour which is characteristic of electrical double layer capacitance. 

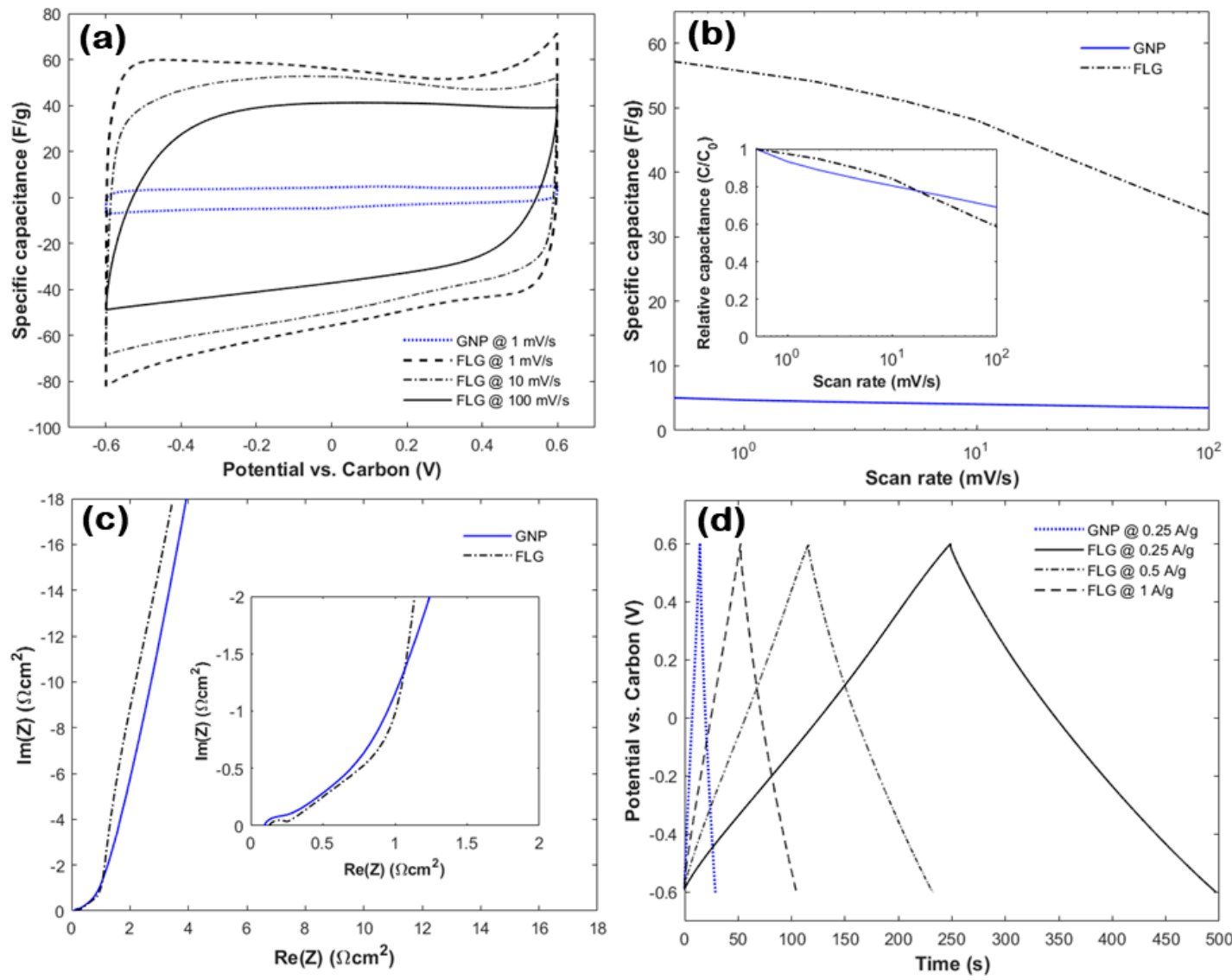

Figure 5. Electrochemical characterization of the FLG and GNP powders based on (a) CV curves with different scan rates $(1,10$ and $100 \mathrm{mV} / \mathrm{s}),(\mathbf{b})$ rate handling tests between 0.5 and $100 \mathrm{mV} / \mathrm{s}$ based on CV, (c) Nyquist plots of the impedance spectra and (d) GCD curves for different specific currents $(0.25,0.5$ and $1 \mathrm{~A} / \mathrm{g})$.

\section{Conclusions}

In this work, two graphene-based materials which differ in terms of morphology and pore structure have been examined for their water purification and electrochemical energy storage performance. The tested samples included smooth, highly-crystalline, non-porous and low-specific surface area $\left(\sim 20 \mathrm{~m}^{2} / \mathrm{g}\right)$ graphene nanoplatelets (GNP) and defective, less-crystalline, nanoporous and high-specific surface area $\left(\sim 776 \mathrm{~m}^{2} / \mathrm{g}\right)$ few-layer graphene flakes (FLG). Both materials were derived from plasma-induced exfoliation of natural flake graphite. The GNP powder showed partial dispersibility in distilled water and ethanol, while the FLG powder was fully dispersible in both solvents even after several weeks. The GNP sample exhibited a higher contact angle with distilled water, however, the FLG sample showed faster kinetics towards water adsorption. In terms of potential applications, the FLG powder has proven to be an efficient filtering material for both decolourization and deacidification of water-rich substances such as Coca-Cola ${ }^{\circledR}$. Moreover, the FLG was used as a proper electrode material for ion electrosorption in a model supercapacitor device. In contrast, the GNP-based filters and electrodes failed in both applications. Therefore, the increased specific surface area and the nano-sized pores of the FLG material seem to be the inherent parameters determining its effectivity towards water purification and energy storage purposes.

Author Contributions: N.N. and N.K. carried out the XRD, dispersion, wettability and filtration tests. C.K. performed the SAXS and electrochemical measurements along with their equivalent analyses. C.T. and T.S. collected the gas sorption data and N.K. performed the respective analysis. C.M., C.R. and O.P. supervised the whole study and provided useful guidance. The first draft of the manuscript was written by N.N., N.K. and C.K. All authors reviewed and commented on the manuscript. 
Funding: This research received no external funding.

Acknowledgments: The authors are thankful to Ian Walters from Perpetuus Carbon Technologies (UK) for providing the graphene-based materials used for this study. The authors are also grateful to Georgios Constantinides from the Cyprus University of Technology (Cyprus) for providing the SEM images presented in this study. Finally, the authors would like to thank Christian Teichert and Caterina Czibula from the Montanuniversität Leoben (Austria) for their help with the contact-angle device.

Conflicts of Interest: The authors declare no conflict of interest.

\section{References}

1. Novoselov, K.S.; Geim, A.K.; Morozov, S.V.; Jiang, D.; Zhang, Y.; Dubonos, S.V.; Grigorieva, I.V.; Firsov, A.A. Electric field effect in atomically thin carbon films. Science 2004, 306, 666-669. [CrossRef]

2. Geim, A.K.; Novoselov, K.S. The rise of graphene. In Nanoscience and Technology; Macmillan Publishers Ltd.: London, UK, 2009; pp. 11-19.

3. Goh, P.S.; Ismail, A.F. Graphene-based nanomaterial: The state-of-the-art material for cutting edge desalination technology. Desalination 2015, 356, 115-128. [CrossRef]

4. Kostoglou, N.; Tarat, A.; Walters, I.; Ryzhkov, V.; Tampaxis, C.; Charalambopoulou, G.; Steriotis, T.; Mitterer, C.; Rebholz, C. Few-layer graphene-like flakes derived by plasma treatment: A potential material for hydrogen adsorption and storage. Microporous Mesoporous Mater. 2016, 225, 482-487. [CrossRef]

5. Kostoglou, N.; Tzitzios, V.; Kontos, A.G.; Giannakopoulos, K.; Tampaxis, C.; Papavasiliou, A.; Charalambopoulou, G.; Steriotis, T.; Li, Y.; Liao, K.; et al. Synthesis of nanoporous graphene oxide adsorbents by freeze-drying or microwave radiation: Characterization and hydrogen storage properties. Int. J. Hydrogen Energy 2015, 40, 6844-6852. [CrossRef]

6. Russo, P.; Hu, A.; Compagnini, G. Synthesis, Properties and Potential Applications of Porous Graphene: A Review. Nano-Micro Lett. 2013, 5, 260-273. [CrossRef]

7. Yi, M.; Shen, Z. A review on mechanical exfoliation for the scalable production of graphene. J. Mater. Chem. A 2015, 3, 11700-11715. [CrossRef]

8. Tetlow, H.; Posthuma de Boer, J.; Ford, I.J.; Vvedensky, D.D.; Coraux, J.; Kantorovich, L. Growth of epitaxial graphene: Theory and experiment. Phys. Rep. 2014, 542, 195-295. [CrossRef]

9. Pei, S.; Cheng, H.-M. The reduction of graphene oxide. Carbon N. Y. 2012, 50, 3210-3228. [CrossRef]

10. Yang, S.; Lohe, M.R.; Müllen, K.; Feng, X. New-Generation Graphene from Electrochemical Approaches: Production and Applications. Adv. Mater. 2016, 28, 6213-6221. [CrossRef] [PubMed]

11. Zhao, G.; Shao, D.; Chen, C.; Wang, X. Synthesis of few-layered graphene by H2O2 plasma etching of graphite. Appl. Phys. Lett. 2011, 98, 183114. [CrossRef]

12. McEvoy, N.; Nolan, H.; Ashok Kumar, N.; Hallam, T.; Duesberg, G.S. Functionalisation of graphene surfaces with downstream plasma treatments. Carbon N. Y. 2013, 54, 283-290. [CrossRef]

13. Hegab, H.M.; Zou, L. Graphene oxide-assisted membranes: Fabrication and potential applications in desalination and water purification. J. Memb. Sci. 2015, 484, 95-106. [CrossRef]

14. Cohen-Tanugi, D.; Grossman, J.C. Water Desalination across Nanoporous Graphene. Nano Lett. 2012, 12, 3602-3608. [CrossRef]

15. Liu, C.; Yu, Z.; Neff, D.; Zhamu, A.; Jang, B.Z. Graphene-Based Supercapacitor with an Ultrahigh Energy Density. Nano Lett. 2010, 10, 4863-4868. [CrossRef]

16. Wang, Y.; Shi, Z.; Huang, Y.; Ma, Y.; Wang, C.; Chen, M.; Chen, Y. Supercapacitor Devices Based on Graphene Materials. J. Phys. Chem. C 2009, 113, 13103-13107. [CrossRef]

17. Han, Y.; Xu, Z.; Gao, C. Ultrathin Graphene Nanofiltration Membrane for Water Purification. Adv. Funct. Mater. 2013, 23, 3693-3700. [CrossRef]

18. Max, L.; Beguin, F.; Frackowiak, E. Supercapacitors: Materials, Systems and Applications; John Wiley \& Sons: Hoboken, NJ, USA, 2013.

19. Suss, M.E.; Porada, S.; Sun, X.; Biesheuvel, P.M.; Yoon, J.; Presser, V. Water desalination via capacitive deionization: What is it and what can we expect from it? Energy Environ. Sci. 2015, 8, 2296-2319. [CrossRef]

20. Lin, Z.; Goikolea, E.; Balducci, A.; Naoi, K.; Taberna, P.L.; Salanne, M.; Yushin, G.; Simon, P. Materials for supercapacitors: When Li-ion battery power is not enough. Mater. Today 2018, 21, 419-436. [CrossRef] 
21. Van der Bruggen, B.; Vandecasteele, C. Distillation vs. membrane filtration: Overview of process evolutions in seawater desalination. Desalination 2002, 143, 207-218. [CrossRef]

22. Greenlee, L.F.; Lawler, D.F.; Freeman, B.D.; Marrot, B.; Moulin, P. Reverse osmosis desalination: Water sources, technology, and today's challenges. Water Res. 2009, 43, 2317-2348. [CrossRef] [PubMed]

23. Lee, K.P.; Arnot, T.C.; Mattia, D. A review of reverse osmosis membrane materials for desalinationDevelopment to date and future potential. J. Memb. Sci. 2011, 370, 1-22. [CrossRef]

24. Mattia, D.; Lee, K.P.; Calabrò, F. Water permeation in carbon nanotube membranes. Curr. Opin. Chem. Eng. 2014, 4, 32-37. [CrossRef]

25. Mattia, D.; Leese, H.; Calabrò, F. Electro-osmotic flow enhancement in carbon nanotube membranes. Philos. Trans. R. Soc. A Math. Phys. Eng. Sci. 2016, 374, 20150268. [CrossRef] [PubMed]

26. Calabrò, F. Modeling the effects of material chemistry on water flow enhancement in nanotube membranes. MRS Bull. 2017, 42, 289-293. [CrossRef]

27. Rivera-Utrilla, J.; Sánchez-Polo, M.; Gómez-Serrano, V.; Álvarez, P.M.; Alvim-Ferraz, M.C.M.; Dias, J.M. Activated carbon modifications to enhance its water treatment applications. An overview. J. Hazard. Mater. 2011, 187, 1-23. [CrossRef]

28. Béguin, F.; Presser, V.; Balducci, A.; Frackowiak, E. Supercapacitors: Carbons and Electrolytes for Advanced Supercapacitors (Adv. Mater. 14/2014). Adv. Mater. 2014, 26, 2283. [CrossRef]

29. How Many Drinks I FAQ I Coca-Cola GB, (n.d.). Available online: https://www.coca-cola.co.uk/faq/howmany-cans-of-coca-cola-are-sold-worldwide-in-a-day (accessed on 12 December 2018).

30. Boyjoo, Y.; Cheng, Y.; Zhong, H.; Tian, H.; Pan, J.; Pareek, V.K.; Jiang, S.P.; Lamonier, J.-F.; Jaroniec, M.; $\mathrm{Liu}, \mathrm{J}$. From waste Coca Cola ${ }^{\circledR}$ to activated carbons with impressive capabilities for $\mathrm{CO}_{2}$ adsorption and supercapacitors. Carbon N. Y. 2017, 116, 490-499. [CrossRef]

31. Myers, D.V.; Howell, J.C. Characterization and specifications of caramel colours: An overview. Food Chem. Toxicol. 1992, 30, 359-363. [CrossRef]

32. Walters, I.; Walters, D.I.; Walters, D. Walters, Particles Comprising Stacked Graphene Layers, US 2017/0174520 A1. 2015. Available online: https://patents.google.com/patent/US20170174520A1/en (accessed on 12 December 2018).

33. Hammersley, A.P. FIT2D: A multi-purpose data reduction, analysis and visualization program. J. Appl. Crystallogr. 2016, 49, 646-652. [CrossRef]

34. Pedersen, J.S. IUCr A flux- and background-optimized version of the NanoSTAR small-angle X-ray scattering camera for solution scattering. J. Appl. Crystallogr. 2004, 37, 369-380. [CrossRef]

35. International Organization for Standardization. Determination of the Specific Surface Area of Solids by Gas Adsorption: BET Method; International Organization for Standardization: Geneva, Switzerland, 2010.

36. Neimark, A.V.; Lin, Y.; Ravikovitch, P.I.; Thommes, M. Quenched solid density functional theory and pore size analysis of micro-mesoporous carbons. Carbon N. Y. 2009, 47, 1617-1628. [CrossRef]

37. Weingarth, D.; Zeiger, M.; Jäckel, N.; Aslan, M.; Feng, G.; Presser, V. Graphitization as a Universal Tool to Tailor the Potential-Dependent Capacitance of Carbon Supercapacitors. Adv. Energy Mater. 2014, 4, 1400316. [CrossRef]

38. Lee, J.; Jäckel, N.; Kim, D.; Widmaier, M.; Sathyamoorthi, S.; Srimuk, P.; Kim, C.; Fleischmann, S.; Zeiger, M.; Presser, V. Porous carbon as a quasi-reference electrode in aqueous electrolytes. Electrochim. Acta 2016, 222, 1800-1805. [CrossRef]

39. Glatter, O.; Kratky, O. Small-Angle X-ray Scattering; Academic Press: New York, NY, USA, 1982; ISBN 978-0122862809.

40. Ismail, I.M.K.; Pfeifer, P. Fractal Analysis and Surface Roughness of Nonporous Carbon Fibers and Carbon Blacks. Langmuir 1994, 10, 1532-1538. [CrossRef]

41. Ruland, W. Small-angle scattering of two-phase systems: Determination and significance of systematic deviations from Porod's law. J. Appl. Crystallogr. 1971, 4, 70-73. [CrossRef]

42. Smarsly, B.; Antonietti, M.; Wolff, T. Evaluation of the small-angle x-ray scattering of carbons using parametrization methods. J. Chem. Phys. 2002, 116, 2618-2627. [CrossRef]

43. Wang, S.; Ábrahám, D.; Vallejos-Burgos, F.; László, K.; Geissler, E.; Takeuchi, K.; Endo, M.; Kaneko, K. Distorted Graphene Sheet Structure-Derived Latent Nanoporosity. Langmuir 2016, 32, 5617-5622. [CrossRef] [PubMed] 
44. Thommes, M.; Kaneko, K.; Neimark, A.V.; Olivier, J.P.; Rodriguez-Reinoso, F.; Rouquerol, J.; Sing, K.S.W. Physisorption of gases, with special reference to the evaluation of surface area and pore size distribution (IUPAC Technical Report). Pure Appl. Chem. 2015, 87, 1051-1069. [CrossRef]

45. Tzitzios, V.; Kostoglou, N.; Giannouri, M.; Basina, G.; Tampaxis, C.; Charalambopoulou, G.; Steriotis, T.; Polychronopoulou, K.; Doumanidis, C.; Mitterer, C.; et al. Solvothermal synthesis, nanostructural characterization and gas cryo-adsorption studies in a metal-organic framework (IRMOF-1) material. Int. J. Hydrogen Energy 2017, 42. [CrossRef]

46. Wang, G.; Shen, X.; Wang, B.; Yao, J.; Park, J. Synthesis and characterisation of hydrophilic and organophilic graphene nanosheets. Carbon N. Y. 2009, 47, 1359-1364. [CrossRef]

47. Förch, R.; Schönherr, H.; Schonherr, H.; Jenkins, A.T. Surface Design: Applications in Bioscience and Nanotechnology; Wiley-VCH: Weinheim, Germany, 2009; ISBN 3527407898.

48. Reddy, A.; Norris, D.F.; Momeni, S.S.; Waldo, B.; Ruby, J.D. The $\mathrm{pH}$ of beverages in the United States. J. Am. Dent. Assoc. 2016, 147, 255-263. [CrossRef]

49. Prehal, C.; Koczwara, C.; Jäckel, N.; Schreiber, A.; Burian, M.; Amenitsch, H.; Hartmann, M.A.; Presser, V.; Paris, O. Quantification of ion confinement and desolvation in nanoporous carbon supercapacitors with modelling and in situ X-ray scattering. Nat. Energy 2017, 2, 16215. [CrossRef]

50. Jäckel, N.; Simon, P.; Gogotsi, Y.; Presser, V. Increase in Capacitance by Subnanometer Pores in Carbon. ACS Energy Lett. 2016, 1, 1262-1265. [CrossRef]

51. Cericola, D.; Spahr, M.E. Impedance Spectroscopic Studies of the Porous Structure of Electrodes containing Graphite Materials with Different Particle Size and Shape. Electrochim. Acta 2016, 191, 558-566. [CrossRef]

(C) 2019 by the authors. Licensee MDPI, Basel, Switzerland. This article is an open access article distributed under the terms and conditions of the Creative Commons Attribution (CC BY) license (http:/ / creativecommons.org/licenses/by/4.0/). 